\title{
Methodology of Complex Evaluation of Sustainable Development of Socio-Environmental-Economic Systems
}

\author{
O.V. Bakanach ${ }^{1, *}$, N.V. Proskurina ${ }^{1}$ and Yu.A. Tokarev ${ }^{1}$ \\ *Corresponding author: bakanach@mail.ru \\ ${ }^{1}$ Samara State University of Economics, Samara, Russia
}

\begin{abstract}
This feasibility study proposes a new approach to the classification of data array concerning sustainable development of socio-environmental-economic systems (hereinafter referred to as SEES) in the area of large river basins. The developed methodology allows carrying out the integrated assessment and forecasting the principal results of the territorial entities functioning and is based on the socioenvironmental-economic conditions and the use of multidimensional comparative analysis of the development of individual territories, which, in its turn, allows considering the regional characteristics of their development. The aim of the study is to determine the conceptual and methodological foundations of integrated assessment of SEES sustainable development in the area of a large river basin. The methods of logical analysis (deduction), non-parametric statistical multidimensional estimation (PATTERN method) and econometric modeling were used in this work. The novelty of the proposed approaches consists in the development of theoretical and methodological guidelines for further improvement of the mechanism of integrated assessment of SEES formation, forecasting its development and sustainable functioning at the regional level. The obtained results allow to rank the territories according to integrated assessment, as well as to develop regional strategic programs.
\end{abstract}

Keywords: ecology, integrated assessment, factors, region, sustainable development.

\section{Introduction}

The formation of a stable socio-economic system should be based on the principles of sustainable development. In recent decades, the idea of sustainability in its various modifications has been becoming a global idea of everyday life, including the human society development studies. In this regard, the application of economic and statistical methods is increasing as a means of methodological and informational study of SEES development, which requires a large array of different data, the choice of which is largely subjective and depends on personal qualities, competencies and scientific orientation of the experts. As a result, forecasts made by different expert groups very often contradict each other or are incorrect.

This situation adversely affects management decisions (at both regional and municipal levels) and can lead to errors and inaccuracies in the territory development planning. This feasibility study considers specifically the areas of large river basins. Rivers as linear components perform the most important functions of environmental corridors being at the same time an essential component of people's lives. They "attract" people, providing them with fresh water and a whole range of services - from fishing and transportation to recreation and appreciation of aesthetic values. The river provides self-development of the landscapes and is the "core" of the environmental framework, as well as being the most important component ("an axis") of its reference framework.

The proposed fundamental scientific research is based on the hypothesis that the environmental vice ecological component of SEES sustainable development of a large river basin is the main one in solving management problems and forecasting the development of the region.

\section{Problem Statement}

The scientific analysis carried out by the authors has shown that today the mentioned above problem, on the one hand, is widely researched, on the other hand, little attention is paid to the methodology of integrated multidimensional assessment of SEES sustainable development, especially concerning large river basin territories. The statistical methods used in scientific works are mainly focused on the biodiversity measurement, assessment of the territorial contamination degree and its presumable socio-economic consequences. At the same time, the question of an integrated quantitative statistical assessment of the regional environmental situation and its territorial differentiation remains open.

A summary review of world research in the field of analysis of sustainable development is given in the under mentioned paper [1]. Consideration of sustainable development in the context of socio-economic situation of the territory is carried out in papers [2, 3].

SEES development study concerning a large river basin - Yangtze-is presented in paper [4], and hardly the other similar works can be found. However the studies on urban SEES sustainable development are carried out more often and it is, as a rule, taking into account the megacities as an example of a study [5,6]. 
The ecological and environmental aspects of sustainable development are reflected in the papers [7,8], and the most significant (from our point of view) is the authors' application of various approaches to the development of quantitative assessment. The links between environmental conditions and living standards of the population of the region are shown in paper [9], and at the state level a similar topic is studied in paper [10]. Aspects of the most global importance are considered in the scientific works devoted to the methodology of measuring SEES sustainable development within the complex-valued development of the territory [11-16].

\section{Research Questions}

In the process of research the authors faced the following questions:

What is decisive in the development of the system of environmental and statistical indicators?

What is the basis for ranking Russian Federation regions according to the sustainable development of their socioenvironmental and economic systems?

What are the most important factors affecting the mechanism of formation of sustainable development of socioenvironmental and economic systems of a large river basin?

\section{Purpose of the Study}

The aim of the study is to determine the conceptual and methodological basis for an integrated assessment of SEES sustainable development of a large river basin.

To achieve this goal of fundamental research, the following tasks are solved:

1) Determination of an information flow scheme to describe SEES sustainable development;

2) Formation of a system of statistical indicators to assess SEES sustainable development and environmental audit;

3) Development of methodological paths of processing and analysis of information for getting a Comprehensive assessment;

4) Carrying out an algorithm of modeling and forecasting of SEES sustainable development on the basis of a Comprehensive assessment;

5) Identification of key determinants which show the change in the level of socio-environmental and economic development of the territory;

6) Approbation of the developed methodology on statistic materials of the Volga Federal district and the Russian Federation.

Concerning the goal fulfillment, the solution of the tasks will offer methodological tools for assessing and forecasting changes in SEES parameters for the whole region in order to achieve its sustainable development. The obtained results will allow in future to have some scientific background in modeling and forecasting application at the regional management level, as well as to give a new impetus to the development of methods of reference framework studies. The novelty of the proposed approaches consists in the development of theoretical and methodological provisions to improve the mechanism of integrated assessment of the formation of SEES, forecasting its development and sustainable operation at the regional level.

\section{Research Methods}

The following research methods are used in the work.

1. The method of logical analysis (deduction).

For a more accurate understanding of the phenomenon under study, we divided them into 2 groups, based on the nature of their impact on the sustainable development of socio-environmental and economic systems:

- "indicators of negative influence "(growth of their values will indicate the deterioration of the situation);

- "indicators of positive impact" (the growth of their values indicates not only a favorable environment, but also a certain increase of attention to environmental issues).

2. Non-parametric statistical method of multidimensional evaluation - method "PATTERN".

Its essence lies in the fact that the initial data of the primary data array on a specific environmental indicator Yi are normalized by dividing by its greatest value. The obtained partial coefficients are averaged, which makes it possible to derive an integrated (integral) assessment of the environmental situation for each subject of the Russian Federation. Thus, the range of possible values is from 0 (worst value) to 1 (best value).

3. Methods of mathematical modeling and forecasting.

The developed system of indicators and methods of calculation of integrated assessment should be studied for the presence of certain mathematical and statistical properties, which will make it possible to select a model class adequate to the goals and objectives of the study, following its requirements, taking into account the characteristics of the analyzed objects. 


\section{Findings}

We have obtained the following system of statistical indicators:

$\mathrm{Y}_{1}$-emissions of pollutants into the air from stationary sources (tons / 1000 people);

$\mathrm{Y}_{2}$-discharge of contaminated wastewater into surface water bodies $\left(\mathrm{m}^{3} /\right.$ person);

$\mathrm{Y}_{3}$-specific weight of water samples that do not meet hygienic standards for sanitary and chemical parameters (\% of the samples studied);

$\mathrm{Y}_{4}$-proportion of the population provided with substandard drinking water (\% of the total population);

$\mathrm{Y}_{5}$-number of registered environmental crimes (units/100,000 people);

$\mathrm{Y}_{6}$ - capture of air pollutants from stationary sources (tons / 1000 people);

$\mathrm{Y}_{7}$-use of fresh water $\left(\mathrm{m}^{3} /\right.$ person);

$\mathrm{Y}_{8}$ - volume of circulating and consistently used water $\left(\mathrm{m}^{3} /\right.$ person);

$\mathrm{Y}_{9^{-}}$use and disposal of production and consumption waste (\% of all waste).

The first group included 5 "indicators of negative impact" on SEES sustainable development $\left(\mathrm{Y}_{1} \ldots \mathrm{Y}_{5}\right)$. The second group is the "indicators of positive influence" on the SEES $\left(\mathrm{Y}_{6} \ldots \mathrm{Y}_{9}\right)$.

The result of the calculations is the ranking of the regions of Russia based on Integrated Assessment (IA) of SEES sustainable development, that is the assigning each subjects (regions) its own rank. We assigned higher rating to regions with higher IA values. Smolensk region is the leader in our rating. The value of its integrated assessment (0.676) can be interpreted as follows: the state of the environmental situation in this subject of the Federation is $64.5 \%$ of the so-called "ideal", the highest possible level in a given year. This "ideal" level would have been achieved if all the environmental indicators had the best values from those presented in the period (the highest or lowest, depending on the specificity of the indicator).

However even having the lowest rating the Arkhangelsk and Kurgan regions cannot be called absolutely disadvantaged regions in the field of environmental protection. On the contrary, the use of fresh water in the Arkhangelsk region falls into the top twenty. In general, this region (with the worst rating) did not occupy the last places on any private indicator, but the final score is very low -0.391 .

Most of the subjects of the Federation belong to the regions of the average type. Though in general, no geographical pattern of distribution of regions based on integrated assessment was found. A more in-depth analysis can be carried out after the accumulation of relevant information for several years and the further detection of a number of typological groups on this basis. Economic, social, natural and climatic and other conditions have their own characteristics in each region and thus produce territorial differentiation of SEES parameters. This raises the problem of systematization of the entire system of causal links. We consider it necessary to "compress information", that is, to find enlarged groups of factors representing the totality of external conditions and circumstances.

According to the hypothesis of our study, the key element of SEES sustainable development of a large river basin is the environmental (ecological) component. The novelty of our idea is that the block of environmental indicators will be considered by us first as effective, determined by the action of a variety of factors, and then as a factorial, in its turn affecting the indicators of demography and health of the population of the territory.

The general regression model of the integrated assessment $\left(\hat{Y}_{I A}\right)$ will be as follows:

$$
\widehat{Y}_{I A}=0,529+0,0018 x_{1}-0,0295 x_{2}+0,0001 x_{3}-0,000003 x_{4} \text {, }
$$

where: $\mathrm{X}_{1}$-electricity production, thousand $\mathrm{kWh} /$ person; $\mathrm{X}_{2}$-freight turnover of motor transport organizations of all types of activities, thousand $\mathrm{km} /$ person; $\mathrm{X}_{3}$-proportion of paved roads in the total length of public roads, \%; $\mathrm{X}_{4}$ average per capita consumer spending, RUB / person;

The short results of modeling of particular indicators are presented in table 1 .

Table 1. Partial coefficients of determination by groups of factors in models of regional indicators

\begin{tabular}{|c|c|c|c|c|c|c|c|c|c|}
\hline Group of factors & $\mathrm{Y}_{1}$ & $\mathrm{Y}_{2}$ & $\mathrm{Y}_{3}$ & $\mathrm{Y}_{4}$ & $\mathrm{Y}_{5}$ & $\mathrm{Y}_{6}$ & $\mathrm{Y}_{7}$ & $\mathrm{Y}_{8}$ & $\mathrm{Y}_{9}$ \\
\hline 1.General economic & --- & --- & --- & 0,064 & --- & --- & --- & --- & --- \\
\hline 2.Demographic & 0,035 & 0,375 & --- & 0,017 & --- & --- & --- & --- & --- \\
\hline 3.Social & --- & --- & --- & --- & 0,226 & 0,053 & 0,135 & --- & --- \\
\hline \begin{tabular}{|l|} 
4. Production and \\
infrastructure
\end{tabular} & --- & --- & 0,095 & 0,073 & 0,019 & 0,049 & 0,168 & 0,461 & 0,124 \\
\hline 5. Financial & 0,230 & --- & 0,116 & --- & --- & --- & --- & --- & 0,256 \\
\hline 6. Natural-climatic & 0,052 & --- & --- & 0,033 & 0,039 & 0,086 & 0,013 & --- & 0,099 \\
\hline \begin{tabular}{|l} 
7. Factors of \\
standard of living
\end{tabular} & --- & --- & --- & 0,008 & --- & --- & --- & 0,020 & 0,013 \\
\hline $\begin{array}{l}\text { 8. Environmental } \\
\text { factors }\end{array}$ & 0,436 & --- & --- & --- & --- & 0,212 & --- & --- & --- \\
\hline Subtotal & 0,753 & 0,375 & 0,211 & 0,195 & 0,284 & 0,400 & 0,316 & 0,481 & 0,491 \\
\hline
\end{tabular}

Source: calculated by the authors on the basis of Rosstat data. 
The summary data on the private coefficients of determination presented in table 1 shows that the most significant impact on the territorial differentiation of SEES sustainable development is shown by the production and infrastructure factors, which are presented in a general model $\left(\mathrm{Y}_{\mathrm{IA}}\right)$ and in 7 private models. This effect looks quite logical, as environmental pollution and its purification are largely associated with the production sector and transport. At the same time, the air and water polluting extractive and processing industries finance and implement certain environmental activities, reducing their harmful effects.

Next in importance are the natural and climatic factors, the influence of which can be seen in 6 private models. The geographical position of the regions, their climate and terrain affect the environmental situation both directly and indirectly, via the cities location and productive forces placement. However, in none of the models this group of factors could explain $10 \%$ of the variation of the effective features.

The opposite situation has developed for a group of environmental factors. They are presented only in two models, and both times current environmental costs play an important role, but their impact is very large - the share of the explained variation is more than $20 \%$.

The least impact on SEES sustainable development is exerted by general economic factors, represented mainly by indicators of the level of economic development of the regions (with a share of variation of $6.4 \%$ ). This can be explained by their refraction through the prism of other factors and not by their directly affect.

The relationship between the state of the environment and the medical and demographic characteristics of the region is generally recognized, but to confirm this thesis, a quantitative justification is needed.

The overall morbidity rate $\left(\mathrm{Z}_{1}\right)$ is quite closely related to the general state of the environment in the region, expressed by the indicator of Integrated assessment $\left(\mathrm{Y}_{\mathrm{IA}}\right)$. The regression equation between them is presented as a linear model:

$$
\hat{Z}_{1}=1243,57-770,77 y_{I A}
$$

The increase of the IA value by 0.1 points leads to a population morbidity decrease with an average of 77.1 people (per 1000 inhabitants). In addition, the level of morbidity is significantly correlated with the amount of pollutants released into the air and with the quality of water.

Life expectancy at birth is inversely related to the "indicators of negative influence", but it is similarly related to the "indicators of positive influence". Aside from that, it has a very weak relationship with integrated assessment $(\mathrm{r}=0,037)$. We can conclude that the environmental (ecological) component is not decisive in the formation of territorial differences in life expectancy.

Medical and demographic indicators, considered as effective can be characterized as inert - it takes time for them to manifest. Thus, environmental factors can affect the incidence of certain diseases not immediately, but having a time lag, a latent period. Therefore, it is necessary to study the duration of this lag to more accurately determine the period of time for which the data are given.

In any case, the impact of the environmental situation on the health and survival of the population cannot be denied. The task of statistics is to quantify this impact and identify the most significant environmental factors.

\section{Conclusion}

1. On the basis of deductive research the information array of environmental data is divided into two groups - the "indicators of negative influence" and the "indicators of positive influence". Based on this, a particular methodological tool was applied to each group of indicators. This is a new approach to the scientific classification of environmental (ecological) data.

2. Within the framework of the nonparametric method "PATTERN" the method of developing an integrated (integral) assessment of socio-environmental and economic systems sustainable development of a large river basin is substantiated for two groups of indicators.

3. The originality of the proposed methods lies in a differentiated approach to the processing of data from different groups of "negative impact indicators" and "positive impact indicators". Based on this, the interpretation of the resulting integrated assessment has been adjusted.

4. The results of the factor analysis allow us to identify the enlarged groups of factors affecting the environmental situation, the demographic situation, as well as public health.

It is the consideration of environmental indicators in two aspects - as effective and as factorial-that is believed to be an element of scientific novelty.

5. Approbation of the results on the example of statistical data on Russia allows obtaining an experimental mathematical model of integrated assessment, which can be implemented in scenario forecasting.

\section{References}

1. T.O. Olawumi, D.W.M. Chan, A scientometric review of global research on sustainability and sustainable development. Journal of Cleaner Production, 183, 231-250. DOI: 10.1016/j.jclepro.2018.02.162 (2018). 
2. B.A. Satyvaldiyeva, Assessment of economic and social situation of regions of Kyrgyzstan. Questions of Economy and Management, 1(8), 117-120 (2017). [in Rus.].

3. L. Slepneva, Socio-economic development of regions of Russia: Assessment of the state and directions of improvement. International Journal of Economics and Financial Issues, 6(55), 179-187 (2016). [in Rus.].

4. Ch. Sun, L. Chen, Y. Tian, Study on the urban state carrying capacity for unbalanced sustainable development regions: Evidence from the Yangtze River Economic Belt. Ecological Indicators, 89, 150-158 (2018).

5. Y. Song, Environmental city and urban sustainable development. Procedia Engineering, 21, 142-146. DOI: 10.1016/j.proeng.2011.11.1997 (2011).

6. N.Yu. Sopilko, M.O. Savukova, Socio-ecological-economic system in the sustainable development megapolis. RUDN Journal of Engineering Researches, 1, 78-83. URL: http://journals.rudn.ru/engineeringresearches/article/view/5170 (2012). [in Rus].

7. X. Wu, S. Liu, F. Cheng, X. Hou, Y. Zhang, S. Dong, G. Liu, A regional strategy for environmental sustainability: A case study in Southwest China. Science of The Total Environment, 616-617, 1224-1234. DOI: 10.1016/j.scitotenv.2017.10.196 (2018).

8. E.A. Zaliznyak, The indicators of environmental aspects of sustainable development of the tourism industry: The European experience. Science Journal of Volgograd State University, Natural Sciences, 1(7), 30-34. DOI: 10.15688/jvolsu11.2014.1.4 (2014). [in Rus.].

9. O.V. Bakanach, N.V. Proskurina, Y.V. Sazhin, M.A. Skvortsova, System diagnostics of the social comfort of living in the region: methodological approach and the results of assessment. International Journal of Economics and Financial Issues, 6(55), 151-156 (2016). [in Rus.].

10. Yu.A. Tokarev, Typology of regions in the Russian Federation on level and dynamics of ecological condition indicators. Izvestiya of Altai State University, 2-2(70), 338-342. Retrieved from: http://izvestia.asu.ru/2011/22/econ/TheNewsOfASU-2011-2-2-econ-15.pdf (2011). [in Rus.].

11. R. Costanza, L. Daly, L. Fioramonti, E. Giovannini, I. Kubiszewski, L. Fog Mortensen, K.E. Pickett, K.V. Ragnarsdottir, R. De Vogli, R.Wilkinson, Modelling and measuring sustainable wellbeing in connection with the UN Sustainable Development Goals. Ecological Economics, 130, 350-355. DOI: 10.1016/j.ecolecon.2016.07.009 (2016).

12. A.C. De Oliveira, C.C. Sokulski, A.A. da Silva Batista, A.C. de Francisco, Competencies for sustainability: A proposed method for the analysis of their interrelationships. Sustainable Production and Consumption, 14, 82-94 (2018).

13. V. Glinskiy, L. Serga, V. Pulyaevskaya, Statistical tools in solving the problems of managing the development of the territories. Voprosy Statistiki, 10, 14-20 (2014). [in Rus].

14. N. Hashemi, Gh. Ghaffary, A proposed sustainable rural development index (SRDI): Lessons from Hajij village, Iran. Tourism Management, 59, 130-138. DOI: 10.1016/j.tourman.2016.07.021 (2017).

15. L.A. Liu, sustainability index with attention to environmental justice for eco-city classification and assessment. Environmental Indicators, 85, 904-914. DOI: 10.1016/j.ecolind.2017.11.038 (2018).

16. R.R. Shaker, A mega-index for the Americas and its underlying sustainable development correlations. Environmental Indicators, 89, 466-479. DOI: 10.1016/j.ecolind.2018.01.050 (2018). 